\title{
Forum
}

\section{Effects at the Landscape Scale May Constrain Habitat Relations at Finer Scales}

\section{Le contexte du paysage peut influencer les relations avifaune-habitat à l'échelle locale}

\author{
Wayne E. Thogmartin $^{1}$
}

Key Words: cross-scale contradictions, spatial scaling, species-habitat relations

The study by Nocera et al. (2007) is an interesting exercise in the commonality and thus transferability of species-habitat relations at different locations. Nocera et al. (2007:Table 4) found that Bobolink (Dolichonyx oryzivorus) occupancy and abundance were consistently associated with the height-density of May vegetation at three widely separated locations. Conversely, the occupancy and abundance of Savannah Sparrow (Passerculus sandwichensis) differed substantially between these disparate locations and was negatively associated with vegetation in some locations and positively in others. Nocera et al. (2007:Discussion) explained this apparent contradiction in habitat relations to site-level factors that they did not study; for instance, they note (my emphasis):

We attribute that vegetation height-density was negatively related with Savannah Sparrow abundance in Iowa and Nova Scotia, but positively associated with Savannah Sparrow abundance in Wisconsin pastures to an artefact either of pastures being so open that birds were using the tallest of what was otherwise very short grass, or were placing their nests in localized tufts of tall grass, but occurring throughout the pasture. This suggests a unimodal relationship between Savannah
Sparrow abundance and vegetation heightdensity that could be tested with additional data from areas with more mid-range vegetation height-density values than those examined here. This again highlights the ubiquity of the importance of vegetation height-density.

Certainly, a unimodal relationship operating at local scales may explain their observations, but other processes may be at work here as well. For instance, their observations could be explained by constraints operating at landscape, rather than local scales (Fig. 1). As Nocera et al. (2007) recognize, area sensitivity may very well be important to this species and may be expressed through constraints on local-scale environmental characteristics.

Wiens (1985) and Wiens et al. (1987) identified cross-scale discrepancies in how birds respond to habitat; since this seminal work, a number of other publications have pointed out the potential for these contradictions (e.g., Cushman and McGarigal 2002, Lichstein et al. 2002, Lawler and Edwards 2006, Thogmartin and Knutson 2007). These reports demonstrated how species differ in the patterns of their associations at different sites and scales. One particularly apt quotation (Wiens et al. 1987:145) is relevant here:

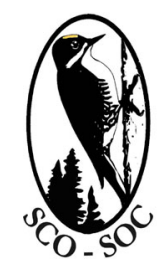

Sponsored by the Society of Canadian Ornithologists and Bird Studies Canada Parrainée par la Société des ornithologistes du Canada et Études d'oiseaux Canada

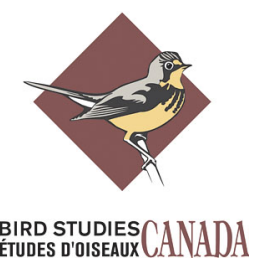


Fig. 1. Patch area sensitivity at the landscape scale may hypothetically influence the relationship between local-scale vegetation height-density and species abundance, explaining the observed habitat relationships of Savannah Sparrow in the study by Nocera et al. (2007).

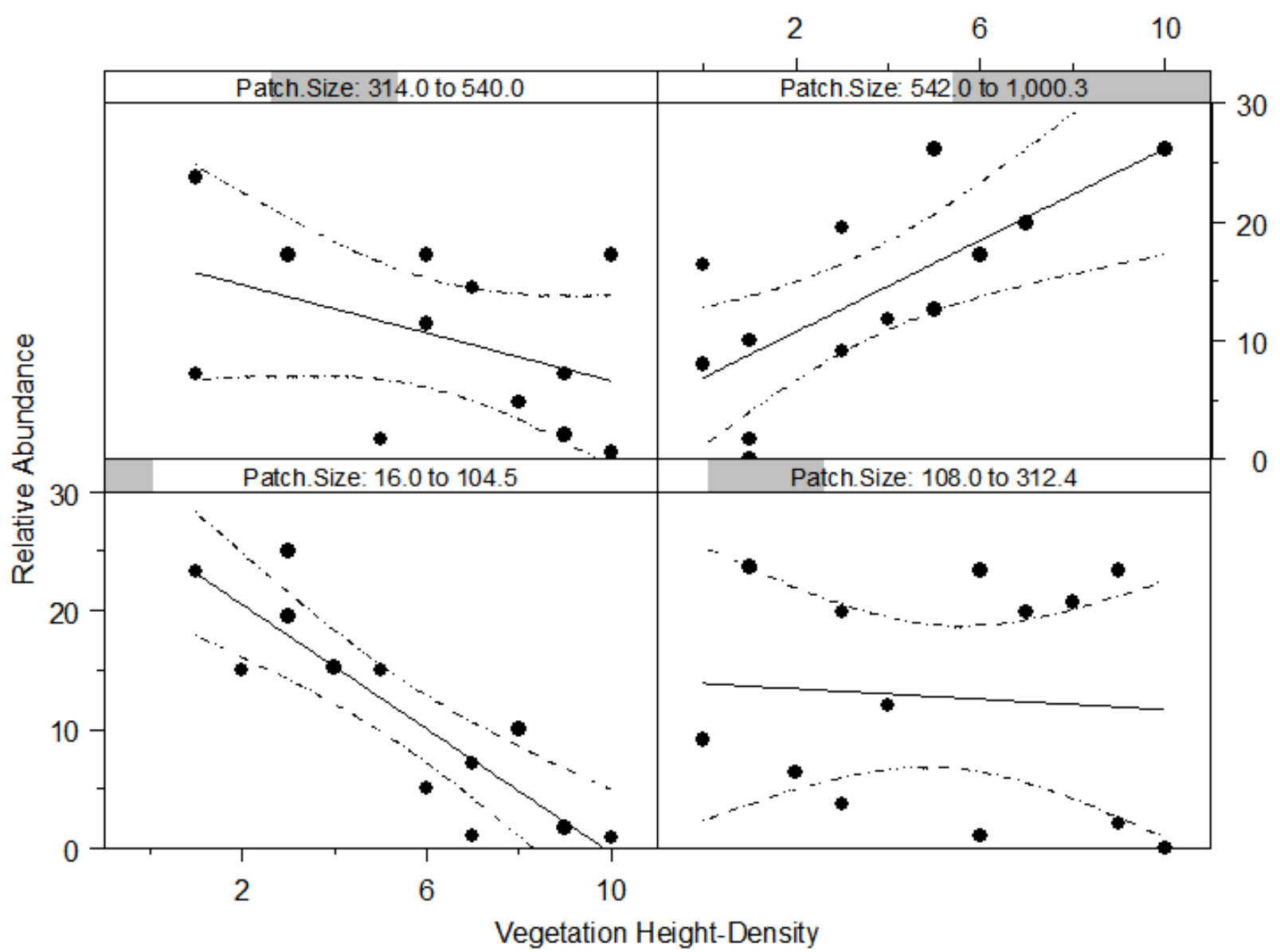

If one attempts to derive patterns at a biogeographic scale by comparing one data set that covers a certain area and range of environmental conditions with another set that encompasses a quite different area and range, the comparison is likely to be invalid and any patterns that do emerge may be artifactual [because of] species-area effects (...) and to the inclusion of different portions of environmental gradients.
Nocera et al. (2007:Table 1) indicated at least some degree of discrepancy in both the mean and range of vegetation characteristics among the Nova Scotia, Iowa, and Wisconsin sites (Fig. 2). The greatest discrepancy in vegetation characteristics occurred in the one variable that was most highly associated with abundance for Bobolink and Savannah Sparrow. 
Fig. 2. Vegetation characteristics (mean and range) at three grassland sites in North America as reported by Nocera et al. (2007). The whiskers represent the range. The reported upper maximum forb cover in Iowa was incorrectly reported, i.e., it was smaller than the mean, but I have imputed a reasonable value for this discussion.
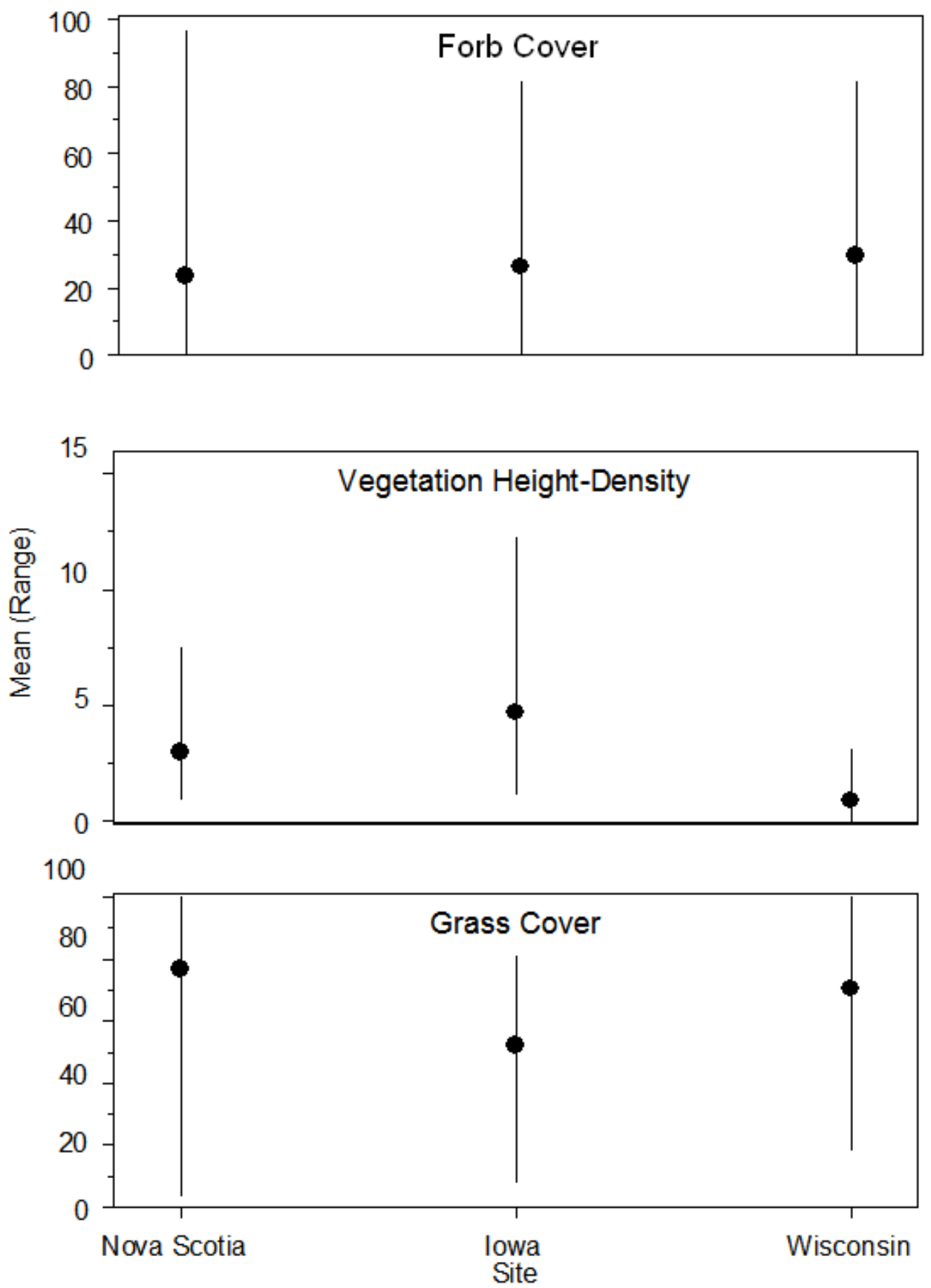
Wiens (1989) also reminds us that ecological patterns at coarse scales are often an average of local heterogeneity; i.e., variability observed at fine scales is smoothed to produce the patterns observed at coarser scales. Saab (1999) and Bakermans and Rodewald (2006), among others, identified how coarse-scale ecological patterns may influence patterns at finer scales. Similar processes may be at play in the study of Nocera et al. (2007).

It is unlikely that a single scale of spatial resolution will entirely characterize the habitat relations of a species (Orians and Wittenberger 1991, Huhta et al. 1998, MacNally and Quinn 1998, Thogmartin and Knutson 2007), and we should endeavor to keep this in mind when we confine our studies to one scale.

Responses to this article can be read online at: http://www.ace-eco.org/vol2/iss2/art6/responses/

\section{LITERATURE CITED}

Bakermans, M. H., and A. D. Rodewald. 2006. Habitat selection by the Acadian Flycatcher: a hierarchical approach. Auk 123:368-382.

Cushman, S. A., and K. McGarigal. 2002. Hierarchical, multiscale decomposition of speciesenvironment relationships. Landscape Ecology 17:637-646.

Huhta, E., J. Jokimäki, and P. Rahko. 1998. Distribution and reproductive success of the Pied Flycatcher Ficedula hypoleuca in relation to forest patch size and vegetation characteristics: the effect of scale. Ibis 140:214-222.

Lawler, J. J., and T. C. Edwards Jr. 2006. A variance-decomposition approach to investigating multiscale habitat associations. Condor 108:47-58.

Lichstein, J. W., T. R. Simons, and K. E. Franzreb. 2002. Landscape effects on breeding songbird abundance in managed forests. Ecological Applications 12:836-857.

MacNally, R., and G. P. Quinn. 1998. Symposium introduction: the importance of scale in ecology. Australian Journal of Ecology 23:1-7.
Nocera, J. J., G. Forbes, and G. Milton. 2007. Habitat relationships of three grassland breeding bird species: broadscale comparisons and hayfield management implications. Avian Conservation and Ecology - Écologie et conservation des oiseaux $\mathbf{2}$ (1): 7. [online] URL: http://www.ace-eco.org/vol2/ iss $1 /$ art $7 /$.

Orians, G. H., and J. F. Wittenberger. 1991. Spatial and temporal scales in habitat selection. American Naturalist 137:S29-S49.

Saab, V. 1999. Importance of spatial scale to habitat use by breeding birds in riparian forests: a hierarchical analysis. Ecological Applications 9:135-151.

Thogmartin, W. E., and M. G. Knutson. 2007. Scaling local species-habitat relations to the larger landscape with a hierarchical spatial count model. Landscape Ecology 22:61-75.

Wiens, J. A. 1985. Habitat selection in variable environments: shrub-steppe birds. Pages 227-251 in M. L. Cody, editor. Habitat selection in birds. Academic Press, Toronto, Canada.

Wiens, J. A. 1989. Spatial scaling in ecology. Functional Ecology 3:385-397.

Wiens, J. A., J. T. Rotenberry, and B. Van Horne. 1987. Habitat occupancy patterns of North American shrubsteppe birds: the effects of spatial scale. Oikos 48:132-147. 